une revue Gallia

Rhône-Alpes | 2007

\title{
Luzinay
}

Brame Faim

\section{Caroline Chamoux}

\section{(2) OpenEdition \\ 12 Journals}

Édition électronique

URL : http://journals.openedition.org/adlfi/7099

ISSN : 2114-0502

Éditeur

Ministère de la culture

Référence électronique

Caroline Chamoux, «Luzinay », ADLFI. Archéologie de la France - Informations [En ligne], Rhône-Alpes, mis en ligne le 01 mars 2007, consulté le 03 mai 2019. URL : http://journals.openedition.org/ adlfi/7099

Ce document a été généré automatiquement le 3 mai 2019.

(C) Ministère de la Culture et de la Communication, CNRS 


\section{Luzinay}

Brame Faim

\section{Caroline Chamoux}

Identifiant de l'opération archéologique : 229693

Date de l'opération : 2007 (PR)

1 L'opération de prospection visait à vérifier la présence de vestiges signalés par le propriétaire. Des fragments de tuiles et de briques ramassés sur le site semblaient antiques, leur quantité importante et la surcuisson de certains laissaient supposer la présence d'un artisanat lié de terres cuites architecturales. L'objectif était donc de vérifier cette hypothèse et de localiser l'occupation.

2 Ces prospections ont concerné un terrain d'environ 4 ha, en pente du sud au nord et d'ouest en est, situé en partie haute d'une colline dominant la vallée de la Sévenne (Fig. $\mathrm{n}^{\circ}$ 1 : Carte de présentation des zones prospectées).

3 L'atelier peut maintenant être localisé sur une zone restreinte grâce aux densités de répartition au sol des fragments; cette zone, située au sud-est du terrain correspond probablement à la zone du four et/ou au dépotoir du fait des nombreux fragments surcuits et agglomérés en « moutons ». Le mobilier témoigne d'un artisanat de céramique centré sur la fabrication de tuiles et de briques et non pas d'un atelier de production mixte.

4 Les prospections ont été précédées d'une étude préalable de l'environnement du site, de son contexte géologique et des sites alentours, ainsi que d'une étude générale sur les ateliers de tuiliers gallo-romains qui ont prouvé que le lieu pouvait être propice à une installation artisanale du fait de la présence proche de tous les matériaux nécessaires à son fonctionnement (combustible, matière argileuse, eau). Rappelons également que les environs de Vienne, dans l'Antiquité, étaient occupés par des villae, des structures de production, des petites agglomérations et des réseaux de circulation. La présence de 
l'atelier dans ce contexte semble donc tout à fait explicable, et l'on peut même supposer un rattachement à une villa proche.

5 À l'issue de cette opération, il ne semble pas possible de dater précisément l'occupation en l'absence de mobilier caractéristique. Le type et le nombre de fours, l'organisation de l'atelier, sa datation et sa durée de fonctionnement ne pourraient être connus que par la mise en œuvre d'autres moyens que les prospections pédestres.

6 CHAMOUX Caroline

\section{ANNEXES}

Fig. $\mathrm{n}^{\circ} 1$ : Carte de présentation des zones prospectées

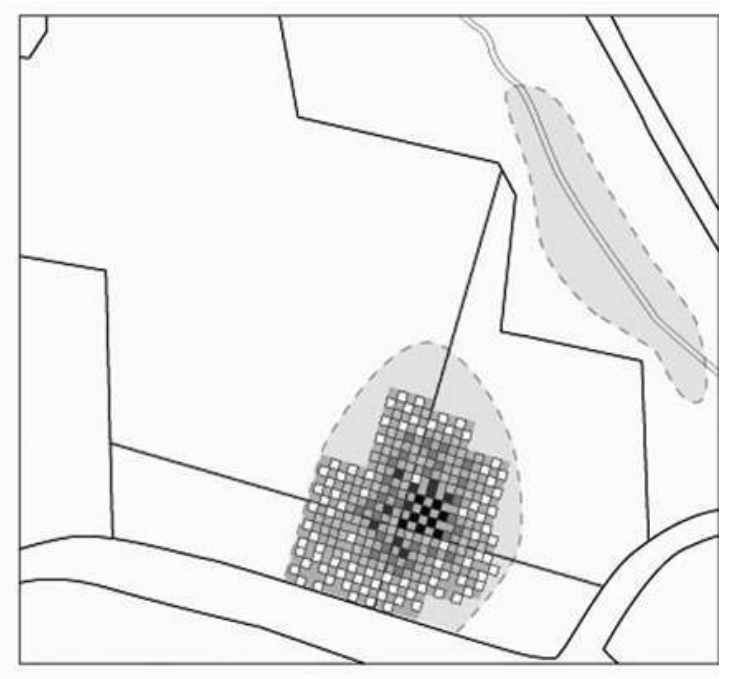

zones prospectées présentant du matériel

carrés non prospectés

carrés prospectés avec dégradé de couleurs représentant la quantité totale de fragments de TCA présentes dans chacun.

axes Nord-Sud et Est-Ouest du carroyage

limites parcellaires du terrain et routes alentours

ruisseau dit "fosse" sur le cadastre

Auteur(s) : Chamoux, caroline. Crédits : ADLFI (2007)

INDEX

Index chronologique : Antiquité romaine

Index géographique : Rhône-Alpes, Isère, Luzinay

operation prospection (PR) 
AUTEURS

CAROLINE CHAMOUX 